\title{
光促进的糖基化反应研究进展
}

\author{
王浩吴品儒赵祥曾静方谦* \\ (华中科技大学药学院 武汉 430030)
}

\begin{abstract}
摘要 糖类化合物与蛋白质、核酸均为基本的生命物质. 糖不仅是生物体内的能量来源与结构物质, 而且在许多生化 过程(分子间识别、细胞间信息传递、免度应答反应、细胞的分化和调亡等)中也发挥着极为重要的作用. 相较于核酸 和蛋白质, 糖类由于其种类的多样性和结构的复杂性, 难有统一、高效的合成方法. 伴随着光化学反应在有机合成中的 应用, 光促进的糖基化反应也吸引了越来越多科研工作者的注意. 主要根据光促进糖基化反应使用的光源(紫外光、可 见光)、催化剂(金属催化剂、非金属催化剂)的类型对近年来光促进糖基化反应的发展和应用进行分类总结和展望.
\end{abstract}

关键词 糖; 糖基化反应; 光化学; 光催化; 可见光促进反应

\section{Advances on Photo-Promoted Glycosylation Reactions}

Wang, Hao Wu, Pinru Zhao, Xiang Zeng, Jing Wan, Qian*

(School of Pharmacy, Huazhong University of Science and Technology, Wuhan 430030)

\begin{abstract}
Carbohydrates, along with proteins and nucleic acids are known as basic life substances, which not only are the energy source and structure material, but also play an extremely important role in many biochemical processes, such as molecules recognition, information transformation in cells, interactions in immune response, differentiation and apoptosis of cells, etc. Compared to proteins and nucleic acids, the synthesis of oligosaccharides in chemical or enzymatic ways is more difficult, due to their diversified and complicated structures. Recently photo especially visible light promoted organic synthesis has become one of the fastest growing fields in organic chemistry attributed to its environmental friendliness, easy availability and low cost. This chemistry has also been applied to the photo-mediated glycosylation reactions by using various light sources (ultraviolet, visible light), photosensitizers (or photocatalysts), and additives (oxidants, reductants etc.), which provides milder and more effective ways for oligosaccharide assembly. To help chemists understand this field, we briefly reviewed recent advances and potential applications of photo-mediated glycosylation reactions according to their types (e.g. light sources, photosensitizers). In this review, we also detailly described the mechanisms and highlighted the advantages and limitations of these reactions. In addition, the further prospects of this area are proposed.

Keywords carbohydrates; glycosylation; photochemistry; photo catalysis; visible light promoted reaction
\end{abstract}

\section{1 引言}

糖是基本的生命物质之一. 在自然界中, 糖以单 糖、寡糖、多糖及糖缀合物(如: 糖脂、糖蛋白及糖肽等) 等形式存在于生物体内. 近年来, 在糖生物学家和糖化 学家的不断努力下, 人们逐渐认识到, 糖不仅是生物体 内的能量来源与结构物质，还在分子间识别、细胞间信 息传递、免疫应答反应、细胞的分化和调亡等生化过程 发挥着极为重要的作用 ${ }^{[1 \sim 4]}$. 然而, 对糖生物功能的进 一步发掘极大地受限于糖类原料的获取. 从自然界直接 获取可供生命科学家研究的均一寡糖和多糖非常困难, 因而人工合成糖类化合物仍然是最有效的手段. 糖的合 成方法主要包括化学合成法和酶合成法. 但相较于核酸 和蛋白质, 糖由于种类的多样性和结构的复杂性而缺乏
统一和高效的合成方法 ${ }^{[5]}$. 糖苷键的构建是糖合成化学 的核心和关键, 代表性的糖苷键的化学合成方法包括 Fischer 法、Koenigs-knorr 法 ${ }^{[6]}$ 、三氯乙酰亚胺酯法 ${ }^{[6 b]}$ 、

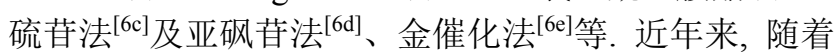
糖化学和糖生物学的快速发展, 一些新型的糖基化方法 也不断涌现 ${ }^{[7]}$. 另外, 国内对于糖化学的研究热度也不 断升温, 近期国内期刊不乏糖基化相关的报道 ${ }^{[8]}$.

光是一种电磁波，可以根据波长分为红外线、可见 光、紫外线. 光化学反应是指物质吸收了光而引起的化 学反应, 光合作用就是典型的光化学过程. 伴随着光化 学反应在有机合成中的广泛应用, 光促进的糖基化反应 由于具有绿色、低毒、反应条件温和等特点, 也吸引了 越来越多科研工作者的注意. 早期的光促进糖基化反应 主要在紫外光下进行, 借助高能量的紫外光直接裂解糖

\footnotetext{
* E-mail: wanqian@hust.edu.cn

Received October 16, 2018; published November 25, 2018.

Project supported by the National Natural Science Foundation of China (Nos. 21472054, 21761132014, 21772050, 21702068), the State Key Laboratory of Bio-organic and Natural Products Chemistry (No. SKLBNPC13425) and Wuhan Creative Talent Development Fund.

项目受国家自然科学基金(Nos. 21472054, 21761132014, 21772050, 21702068)、生命有机化学国家重点实验室开放基金(No. SKLBNPC13425)和武汉市 创新人才开发资金的资助.
} 
基供体端基基团或者激发光催化剂进行电子传递形成 糖基正离子, 糖基正离子继而与糖基受体反应形成相应 的糖苷化产物. 近十年来, 在 MacMillan ${ }^{[9]}$, Yoon ${ }^{[10]}$, Stephenson ${ }^{[11]}, \mathrm{Xiao}^{[12]}$ 等科研工作者的共同努力下，可 见光催化迈入了快速发展阶段. 随着可见光催化技术的 应用，可见光促进的糖基化反应也取得了迅速的发 展 ${ }^{[13]}$. 本文根据光促进的糖基化反应中所使用的光源 和光催化剂类型, 对近年来光促进的糖基化反应进行总 结与归纳.

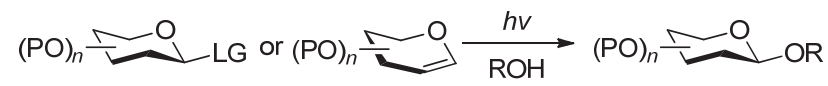

LG = Leaving group

图式 1 光促进糖基化反应

Scheme 1 Photo-promoted glycosylation

\section{2 紫外光促进的糖基化反应}

紫外光具有波长短、能量高、穿透力强等特点, 被 最早应用于光化学反应. 在光促进的糖基化反应研究的 早期阶段, 科研工作者也主要利用紫外光自身的高能量 特点或者结合使用有机光敏剂来达到活化糖基供体的 目的.

\section{1 紫外光直接活化糖基供体}

紫外线能量较高, 可以直接裂解一些特定类型的端 基糖苷键, 从而活化糖基供体. 1999 年 Yamago 研究小 组 ${ }^{[14]}$ 直接利用紫外光并在加热条件下, 使得全乙酰基 保护的芳基碲糖苷 $\mathbf{1}$ 的 $\mathrm{C}-\mathrm{Te}$ 键发生均裂形成端基碳自 由基, 并与自由基捕获剂 TEMPO 或硒化物等反应形成 新的糖苷键(Scheme 2).
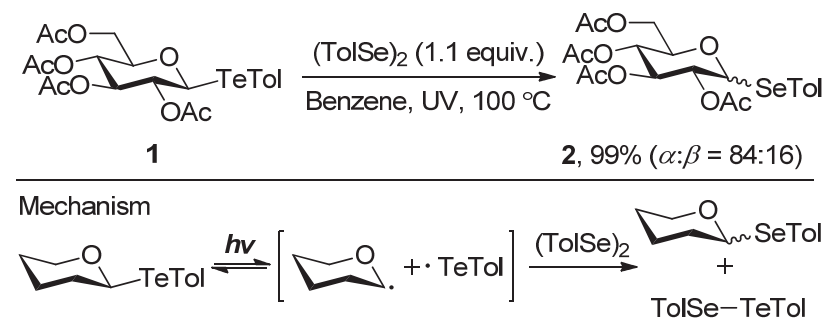

图式 2 紫外光与加热条件下硒糖苷的形成

Scheme 2 Synthesis of selenoglycoside under UV and heating

脱氧糖是很多天然产物和抗生素的重要组成部分, 利用光促进的糖基化方法合成脱氧糖也吸引了很多科 研工作者注意. 2013 年 Toshima 课题组 ${ }^{[15]}$ 以非保护的 2脱氧硫苷 3 为供体, 使用 4-甲氧基苯基硼酸 $\mathbf{5}$ 作为反应 中糖基供体的临时保护基，2,3-二氯-5,6-二氰基对苯醌 (DDQ)为氧化剂, 利用单电子转移机理, 在紫外光促进 下，“一锅法” 完成了 2-脱氧糖苷的合成(Scheme 3). 4甲氧基苯基硓酸 5 能够与糖基供体 C4 和 C6 位羟基结 合形成中间体 6 , 起到临时保护基的作用, 能够有效抑 制分子内合环产物 7 的生成.
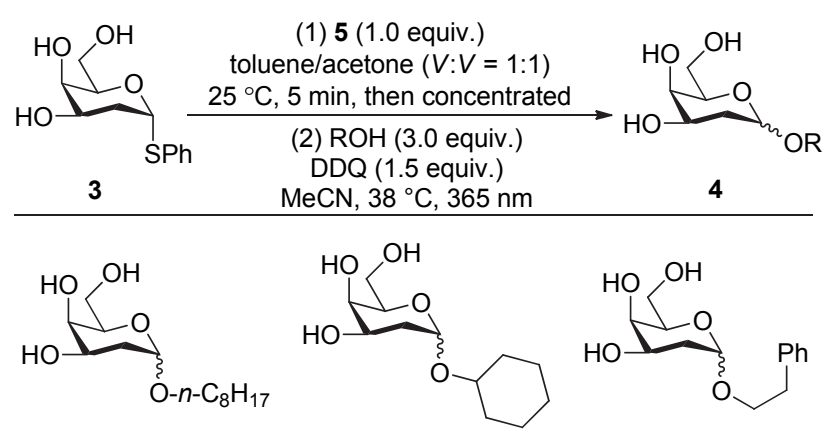

4a, $80 \%(\alpha: \beta=75: 25) \quad$ 4b, 71\% $(\alpha: \beta=86: 14)$ 4c, $84 \%(\alpha: \beta=81: 19)$
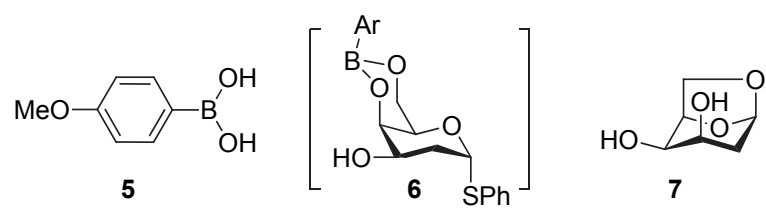

图式 3 紫外光促进下无保护基的 2-脱氧硫苷供体的氧糖苷化反应 Scheme 3 UV-induced $O$-glycosylation of unprotected 2-deoxythioglycoside

2015 年叶新山课题组 ${ }^{[16]}$ 利用紫外光裂解硫苷供体 $\mathrm{C}-\mathrm{S}$ 键，形成糖端基碳自由基，碳自由基继而被氧化 剂三氟甲磺酸铜氧化成糖基碳正离子，再与受体反应生 成糖苷键; 而均裂形成的苯基硫自由基则发生自身偶合 形成二硫醚. 在此反应中糖基供体可以与多种类型受体 (包括胆固醇、氨基酸及各种糖类受体等)反应，以中等 至较高产率得到糖苷化产物. 在该反应条件下酰基、苄 基、异亚丙甲基、双键等基团都有良好的耐受性. 作者 也通过详细的控制实验证实反应是自由基历程，而三氟 甲磺酸铜作为氧化剂参与氧化碳自由基 (Scheme 4).
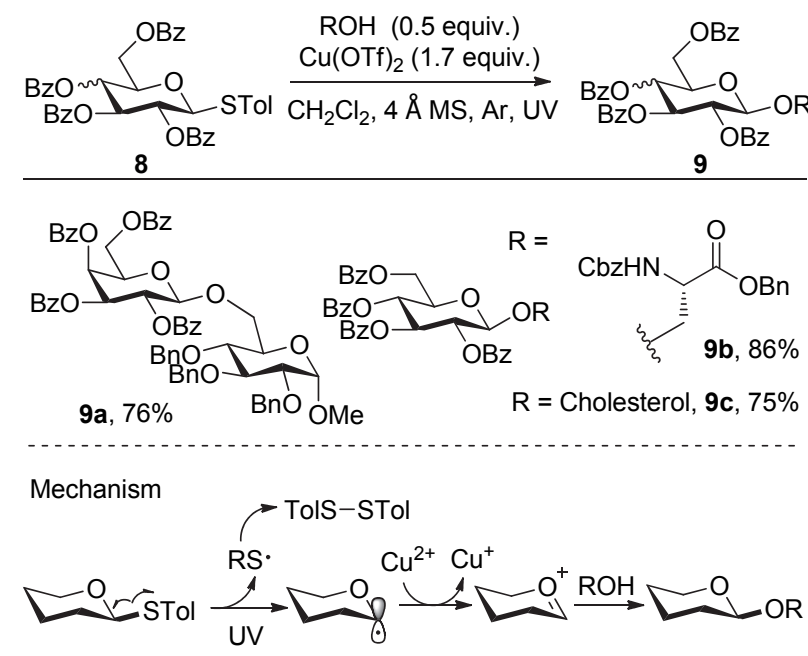

图式 4 紫外光引发的硫苷 $\mathrm{C}-\mathrm{S}$ 键裂解

Scheme 4 Photoinduced $\mathrm{C}-\mathrm{S}$ bond cleavage of thioglycosides

叶新山课题组 ${ }^{[17]}$ 在前期研究的基础上进一步发展 了光促进自由基加成糖基化方法. 三氟甲基自由基具有 较高的亲电性及较好的亲硫性，作者综合考虑反应物的 氧化还原电位，使用 Umemto's 试剂作为三氟甲基自由 基前体物. 在紫外光照射下，使用 1.3 equiv.的供体及 

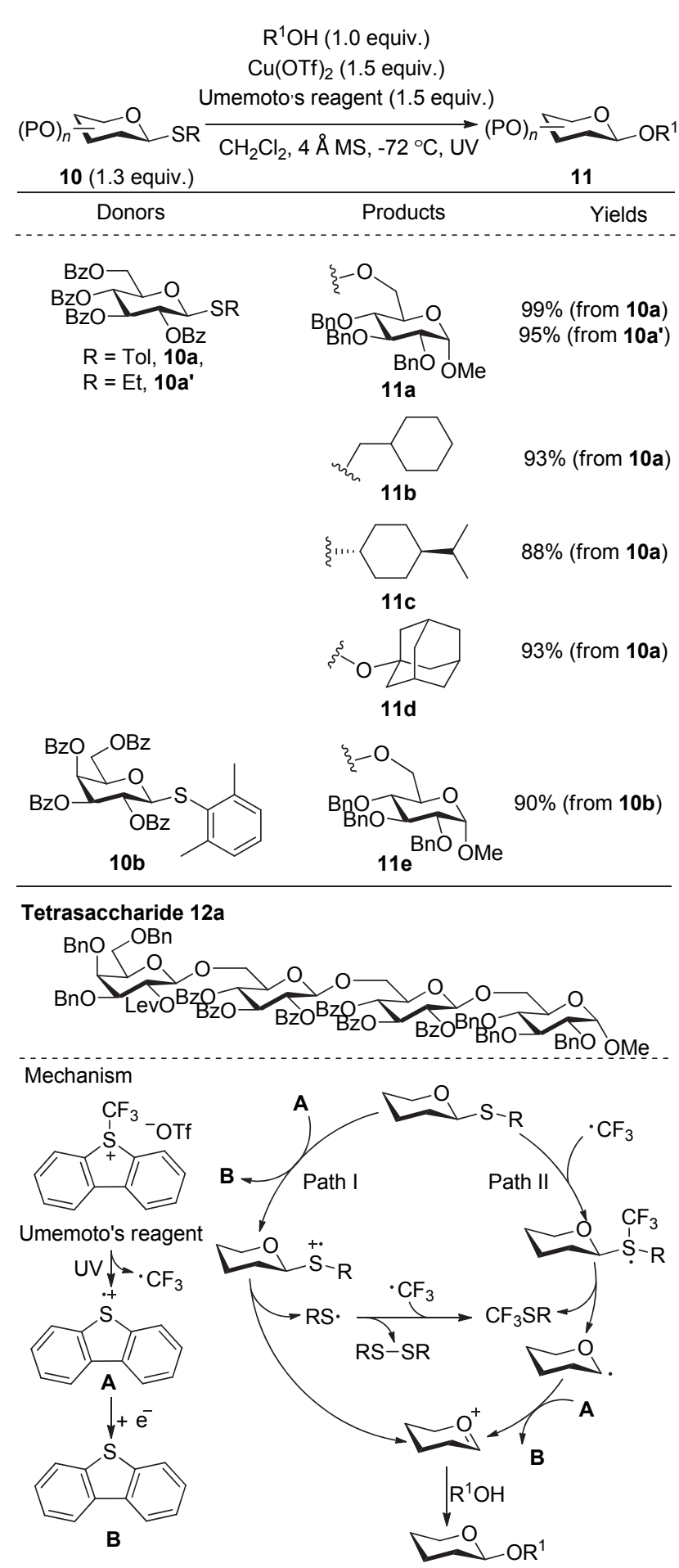

图式 5 紫外光促进的自由基参与的糖基化反应

Scheme 5 UV-promoted glycosylation through radical-participated pathway

1.5 equiv. 自由基前体 Umemto's 试剂, 在一 $72{ }^{\circ} \mathrm{C}$ 下反应 时效果较好, 添加氧化剂三氟甲磺酸铜能够在一定程度 上提高反应效率. 此外, 采用 “预活化” 策略可以使得 糖苷化产率进一步提高. 在此基础上, 使用不同类型的 硫苷供体(-SAr、-SEt、-SPy)与多种糖基受体反应，均可 在短时间内高立体选择性、高产率地得到糖苷化产物。 最后，作者基于 “预活化一锅法” 的策略，以 $61 \%$ 的产
率完成了四糖 12a 的合成(Scheme 5).

\section{2 非金属光敏剂参与的糖基化反应}

光敏剂是一类具有高共轭结构的催化剂，根据结构 可分为: 简单芳香生色团、官能化的有机染料、无机簇 和过渡金属配合物. 相较于其它有机小分子，光敏剂可 以更高效温和地吸收波长更长的光线, 并通过能量或电 子转移激活特定的基团.

Noyori 课题组 ${ }^{[18]}$ 于 1985 年报道了紫外光促进的光 敏性染料催化的糖基化方法. 该方法使用 $200 \mathrm{~W}$ 高压录 灯为紫外光源, 在光敏性染料菲 $(\mathrm{P})$ 和对苯二腈 $(\mathrm{DCNB})$ 共催化作用下，甲基醚保护的芳基-2-脱氧糖供体 13 与 烷基醇类受体反应, 合成 2-脱氧糖苷类化合物 14. 首先 光敏性染料菲 $(\mathrm{P})$ 受光激发, 随后被 DCNB 氧化成自由 基阳离子 $\left(\mathrm{P}^{{ }^{+}}\right)$, 该自由基阳离子接着被糖基供体 $\mathbf{1 3}$ 的 芳基还原回 $\mathrm{P}$, 而糖基供体则转化中间体 $\mathbf{C}$ 并进一步裂 解产生苯基氧自由基 $\mathbf{D}$ 和氧鎓离子 $\mathbf{E}$, 后者与醇类受体 反应生成糖苷化合物; 与此同时, DCNB 自由基阴离子 被苯基氧自由基氧化成 DCNB, 并进入下一个催化循环 (Scheme 6).

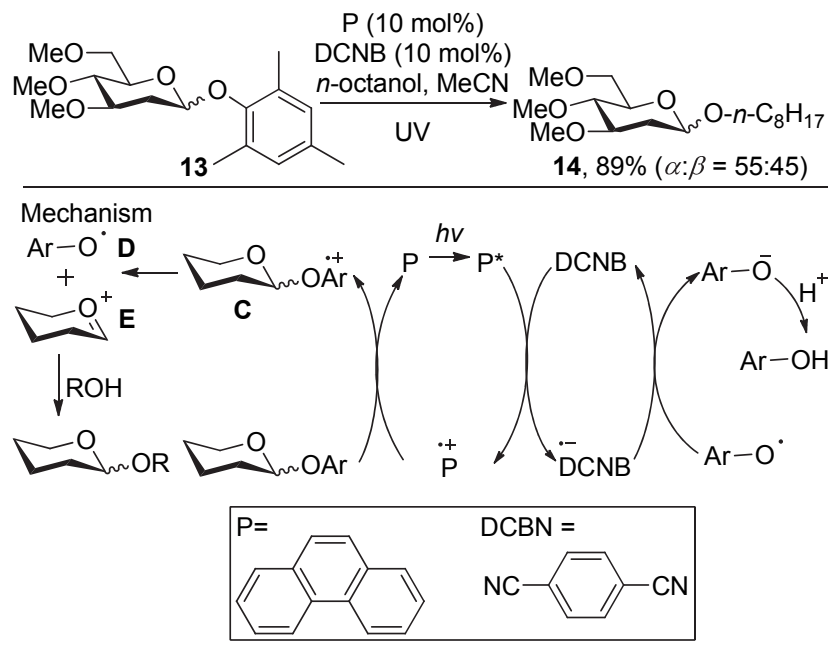

图式 6 菲与对苯二腈介导的光促进糖基化反应

Scheme 6 Phenanthrene and DCNB mediated photo-promoted glycosylation

糖基硫化物(硫苷、硒苷等)由于具有较高的稳定性, 是目前应用最为广泛的糖基供体之一. 1990 年, Griffin 小组 ${ }^{[19]}$ 报道了在紫外光 $(350 \mathrm{~nm})$ 引发下, 使用全甲基醚 保护的硫苷供体 15, 以 1,4 -二氧基萗 $(\mathrm{DCN})$ 作为光催化 剂，甲醇与乙腈为混合溶剂，合成甲基糖苷化产物 16 的 方法. 作者指出, 在紫外光的作用下, DCN 与供体 15 之 间发生电子转移, 生成 DCN 自由基阴离子和自由基阳 离子中间体 F，随后中间体 $\mathbf{F}$ 发生裂解产生苯基硫自由 基和氧鎓离子，后者与甲醇反应生成糖苷化合物 $\mathbf{1 5}$; 而 DCN 自由基阴离子则被苯基硫自由基氧化成 DCN, 完 成催化循环(Scheme 7). 另外, 作者研究发现, 乙酰基 保护的硫苷供体在此条件下完全不反应，而苠基保护的 
硫苷供体则不耐受此反应条件.

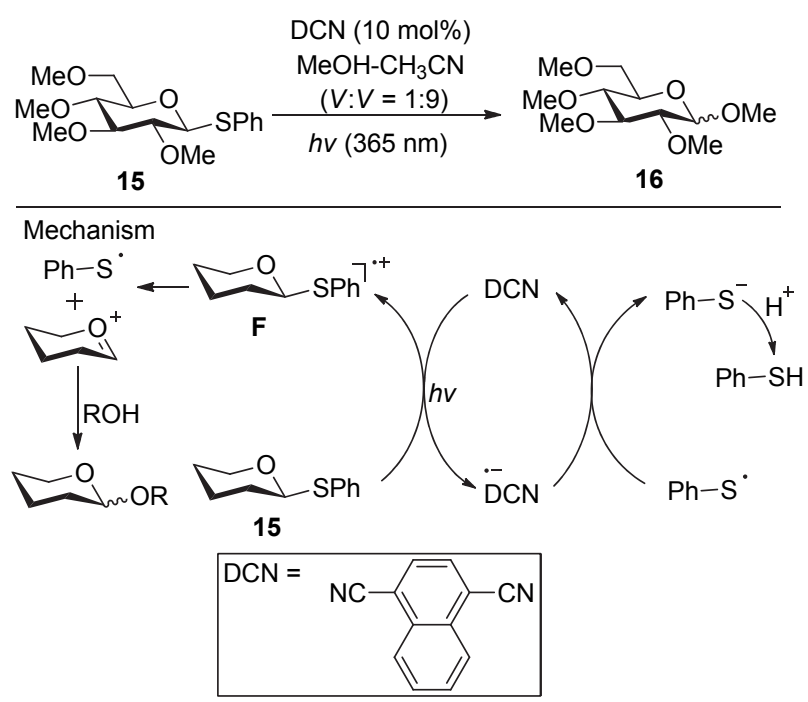

图式 7 DCN 介导的光促进糖基化反应

Scheme 7 DCN mediated photo-promoted glycosylation

硫族糖苷中除了硫糖苗以外, 硒糖苷在糖基化反应 中应用也较多. 烷基硒化物的氧化势能低于烷基醚化 物, 并且 $\mathrm{C}-\mathrm{Se}$ 键的键裂解能低于 $\mathrm{C}-\mathrm{O}$ 键的裂解能; 此外, 硒糖苷具有很好的稳定性, 能够耐受很多保护去保护条件. 基于硒糖苷的多种优势, Furuta 和 Iwamura 课题组 ${ }^{[20]}$ 使用全甲基保护的芳基硒糖苷供体 17 , 以 2 , 4,6-三苯基吡喃鎓四氟硼酸盐(TPT)为光敏剂, 在 $100 \mathrm{~W}$ 高压录灯照射下与糖基受体反应, 得到以 $\beta$-构型为主的 糖苷化产物 18 (Scheme 8). 反应过程中, 光敏剂(TPT) 受光激发, 并氧化硒糖苷供体 17 生成自由基阳离子中 间体 $\mathbf{G}$, 进一步裂解产生氧鎓离子和苯基硒自由基, 前 者与糖基受体反应生成糖苷化合物, 而后者自身偶联成 二苯基二硒醚. 其中化合物 $\mathbf{1 8 d}$ 是第一例采用光化学方 法合成的二糖. 此方法与此前的方法相比, 受体适用范 围更广, 一级、二级醇以及糖类受体均可以中等至较高 产率发生糖苷化反应.

Crich 课题组 ${ }^{[21]}$ 于 2011 年应用全甲基醚保护的和全 苄基醚保护的苯基硒糖苷供体 19 , 以 $N$-甲基喹啉六氟 嗍酸盐 $\left(\mathrm{NMQ}-\mathrm{PF}_{6}\right)$ 为光敏剂, 甲苯为共敏剂, 乙腈为溶 剂, 在空气环境中, $350 \mathrm{~nm}$ 荧光灯照射下与各种受体反 应, 生成多种以 $\beta$ 构型为主的糖苷化合物. 作者研究发 现, 使用氩气代替空气参与反应, 反应基本不进行; 甲 苯可以作为共敏剂, 无甲苯参与的情况下, 反应速率明 显变慢; 使用乙腈作为溶剂可促进 $\mathrm{NMQ}^{-} \mathrm{PF}_{6}$ 的溶解. 但是, 氧气参与还原反应会导致水的产生, 因而水解产 物的生成难以避免. 在制备得到 $(1 \rightarrow 6)-O$-连接二糖产物 后, 作者尝试使用硒糖苷供体与含有二级醇羟基的糖类 受体反应, 但反应副产物较多, 没有得到相应的二糖产 物. 此外, 在相同的反应条件下, 全芐基和全苯甲酰基 保护的硫苷供体不能被很好的活化(Scheme 9).

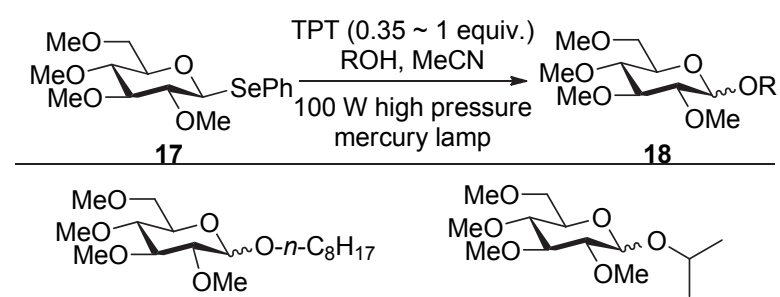

18a, $68 \%(\alpha: \beta=30: 70)$

18b, $71 \%(\alpha: \beta=30: 70)$

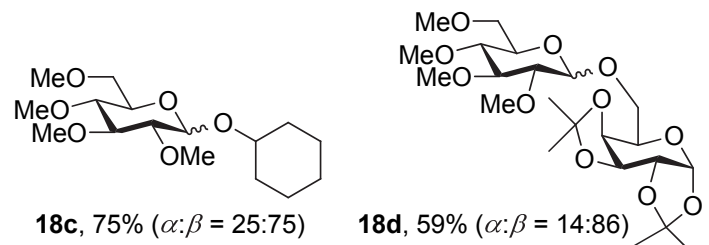
Mechanism

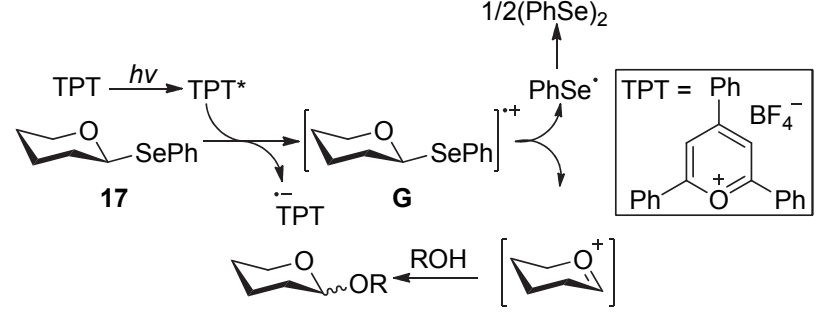

图式 $82,4,6$-三苯基吡喃四氟硼酸盐介导的光促进糖基化反应 Scheme 8 TPT mediated photo-promoted glycosylation
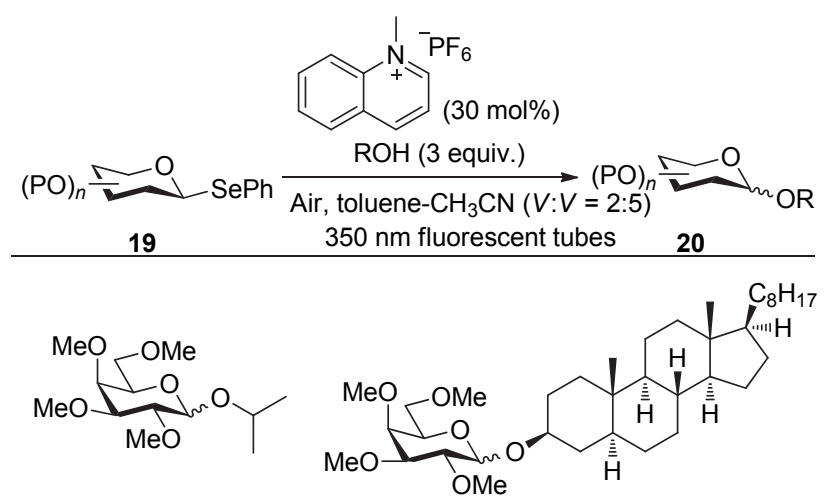

20a, $73 \%(\alpha: \beta=1: 1.6)$

20b, $51 \%(\alpha: \beta=1: 2.0)$

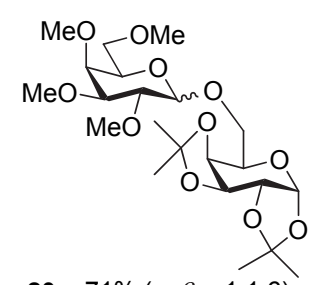

20c, $71 \%(\alpha: \beta=1: 1.6)$

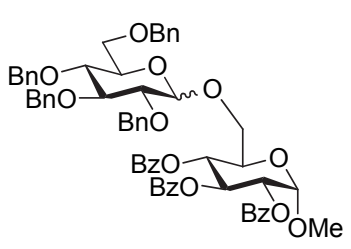

20d, $45 \%(\alpha: \beta=1: 2.4)$
图式 $9 \mathrm{~N}$-甲基喹啉六氟硼酸盐介导的光促进糖基化反应

Scheme 9 NMQ-PF6 mediated photo-promoted glycosylation

三氯乙酰亚胺酯、乙酸酷等是广泛使用的糖基供体, 这些供体通常使用路易斯酸或质子酸活化. 䒬酚类化合 物酸性较弱, 但研究发现在光的激发作用下，该类化合 物酸性得到增强, 更易释放出氢质子. 利用这一原理, Toshima 课题组 ${ }^{[22]}$ 使用可回收利用的有机光酸-— - - 萗 酚(2-Naphthol)顺利活化三氯乙酰亚胺酯类糖基供体 21, 
高效得到糖苷化合物 22(Scheme 10). 该反应与使用樟 脑磺酸、TMSOTf 等为活化剂时的效率相当, 但反应完 成后不需要加入碱终止反应，且菜酚可以高效回收.

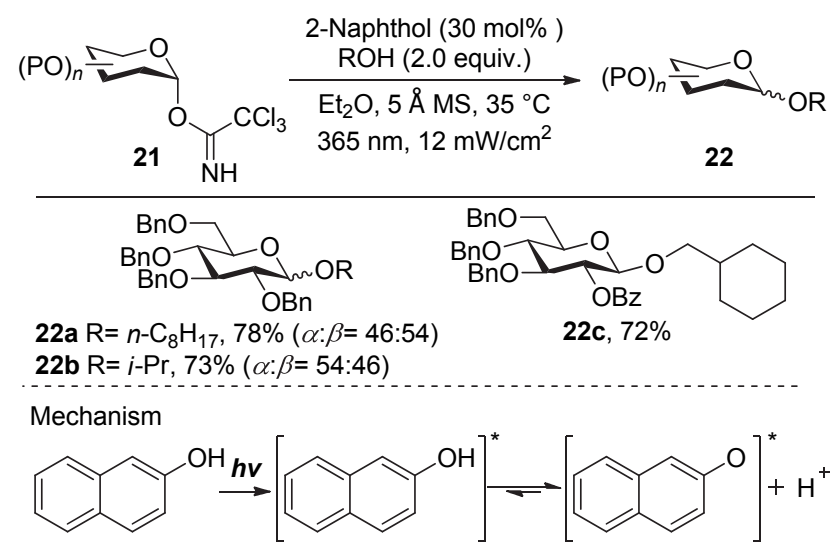

图式 102 -䒬酚介导的光促进糖基化反应

Scheme 10 2-Naphthol mediated photo-promoted glycosylation

虽然应用䒺酚类有机光酸作为催化剂可以高效地 构建糖苷键, 但是在糖基供体没有邻基参与基团存在 时, 反应产物的立体选择性较难控制, $\alpha / \beta$ 比例接近 1 : 1. Toshima 课题组 ${ }^{[23]}$ 进一步发展了以芳基硫脲为有机光 酸的糖基化方法. 该方法能够高产率地构建糖苷键, 更 重要的是可以通过反应动力学控制产物的立体构型. 在 紫外光照下芳基硫脲酸性增强, 进而活化亚胺酯供体, 高浓度下反应经由 $\mathrm{S}_{\mathrm{N}} 2$ 历程得到 $\beta$-选择性产物; 低浓度 下反应经由 $\mathrm{S}_{\mathrm{N}} 1$ 历程得到 $\alpha$-选择性产物(Scheme 11). 此 外, Toshima 等发现低浓度下加入 $5 \AA$ 分子笁(有弱酸性)

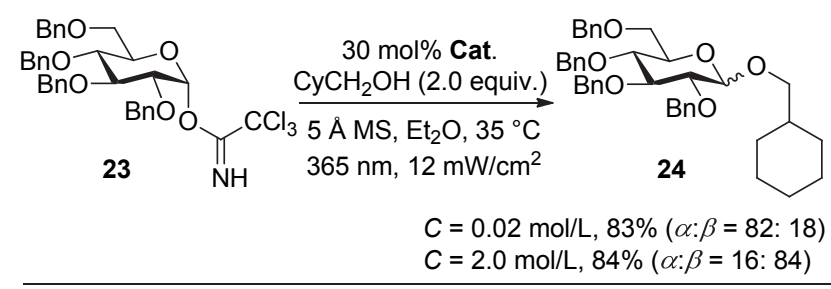

$$
\begin{aligned}
& \text { Mechanism }
\end{aligned}
$$

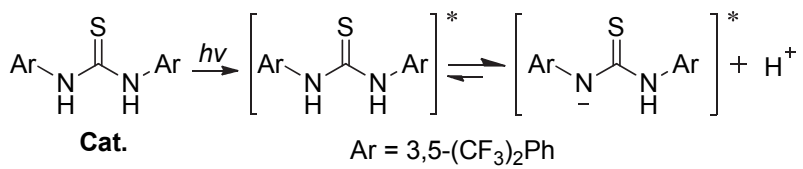

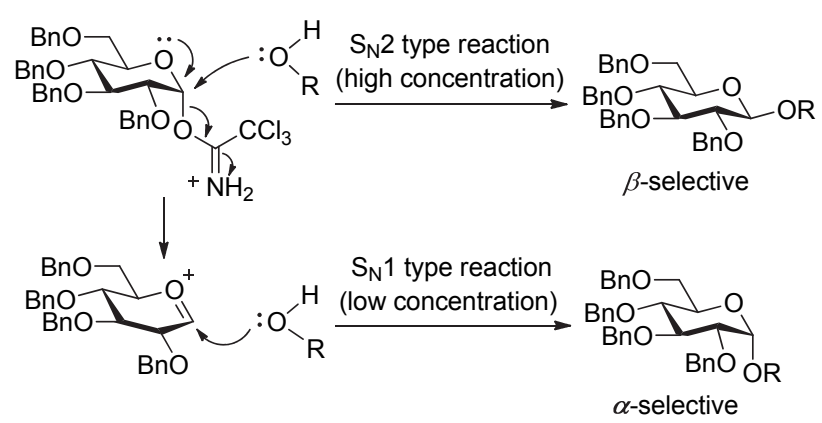

图式 11 芳基硫嫝介导的光促进糖基化反应

Scheme 11 Aryl urea mediated photo-promoted glycosylation
有助于 $\alpha$-构型产物生成; 而高浓度下不使用分子篮, $\beta$ 构型产物能更有效形成.

\section{3 可见光促进的糖基化反应}

近年来，在科研工作者的不解努力下，紫外光促进 的糖基化反应取得了较大进展，但是紫外光能量高导致 副反应较多, 并且其天然丰度低、安全性差, 这些缺点 限制了它的进一步利用. 相较于紫外光, 可见光具有天 然丰度高、使用简便、环境友好等特点, 随着可见光催 化在有机合成化学中的成功运用, 可见光促进的糖基化 反应也吸引了越来越多糖化学工作者的注意.

\section{1 非金属催化剂参与的糖基化反应}

烯糖作为糖基供体，已经被成功应用于多种 2-脱氧 糖苷类化合物的合成中 ${ }^{[24]} .2018$ 年, Wang 课题组 ${ }^{[25]}$ 报道 了以烯糖作为供体, 有机光酸 Eosin $Y$ 为光催化剂, 二 苯基二硫醚 $(\mathrm{PhSSPh})$ 为共催化剂, 在可见光照射下, 高 立体选择性合成 2-脱氧糖苷的方法. 该方法反应条件温 和、底物适用范围广、基团耐受性好. 基于相关实验结 果，作者提出了反应的可能机理: 首先，在可见光激发 下, Eosin Y 跃迁至激发态, 激发态*Eosin $\mathrm{Y}$ 去质子化生 成 $\mathbf{H}$, 而生成的质子则将烯糖 $\mathbf{2 5}$ 活化生成氧鎓离子中 间体 $\mathbf{K}$, 接着 $\mathbf{K}$ 与糖基受体反应生成中间体 $\mathbf{L}$, 最后去 质子化生成糖苷化产物 26. 共催化剂 PhSSPh 在光的作 用下发生均裂, 生成苯基硫自由基 $\mathbf{M}, \mathbf{M}$ 接着将中间体 $\mathbf{H}$ 氧化, 自身转化为苯基硫负离子 $\mathbf{N}, \mathbf{H}$ 则被氧化成 $\mathbf{I}$, 苯基硫负离子 $\mathbf{N}$ 则会与中间体 $\mathbf{L}$ 发生质子传递生成苯 硫酚，苯硫酚接着与中间体 $\mathbf{J}$ 发生快速的氢原子传递, 生成苯基硫自由基 $\mathbf{M}$ 和 Eosin $\mathrm{Y}$, 并进入下一次催化循 环(Scheme 12).

\section{2 金属催化剂参与的糖基化反应}

碳糖苷是一类具有重要生物活性的化合物, 广泛存 在于天然产物中. 2010 年 Gagné 课题组 ${ }^{[26]}$ 应用可见光催 化法, 以 $\mathrm{Ru}(\mathrm{bpy})_{3}\left(\mathrm{BF}_{4}\right)_{2}$ 为催化剂, $N, N$-二异丙基乙胺 (DIPEA)为还原剂, Hantzsch ester 为添加剂, 将全苯甲 酰基保护的 $\alpha$-溴代葡萄糖 27 与缺电子烯烃反应，高效 率、高立体选择性地合成多种类型的 $\alpha$-碳糖苷类化合物 28. 其中 Hantzsch ester 的加入能够有效抑制碳苷低聚 物的形成，有效提高反应效率. 具体的反应历程如下:

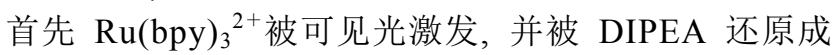

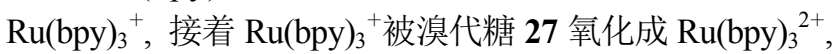
完成此次催化循环. 而起氧化作用的溴代物被还原生成 糖端基碳自由基和溴负离子, 糖端基碳自由基则进一步 与缺电子的烯烃发生加成反应, 并㩲取氢原子而生成 $\alpha$ 碳糖苷类化合物(Scheme 13). 随后在 2012 年, 该课题 组发展了一种连续光照反应器下进行的光催化反应, 通 过增加对光子的吸收和利用提高光促反应效率, 最终能 够一次性合成克级的碳糖苷 $\mathbf{2 8 c}$ (Scheme 14). 此连续光 


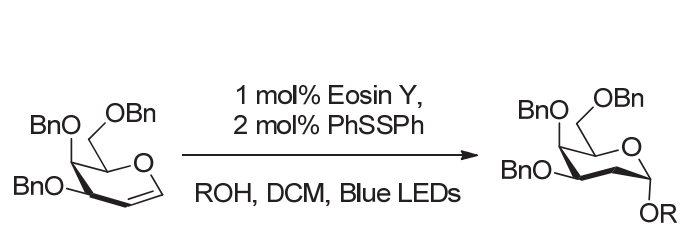

25
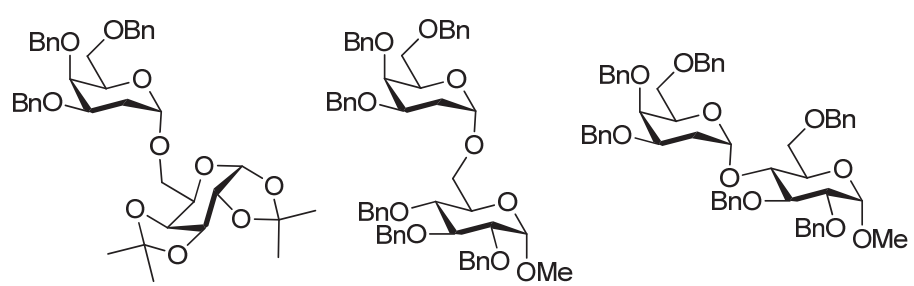

26a, 90\% ( $\alpha: \beta>20: 1) \quad$ 26b, 88\% $(\alpha: \beta>30: 1) \quad$ 26c, $67 \%(\alpha: \beta>20: 1)$

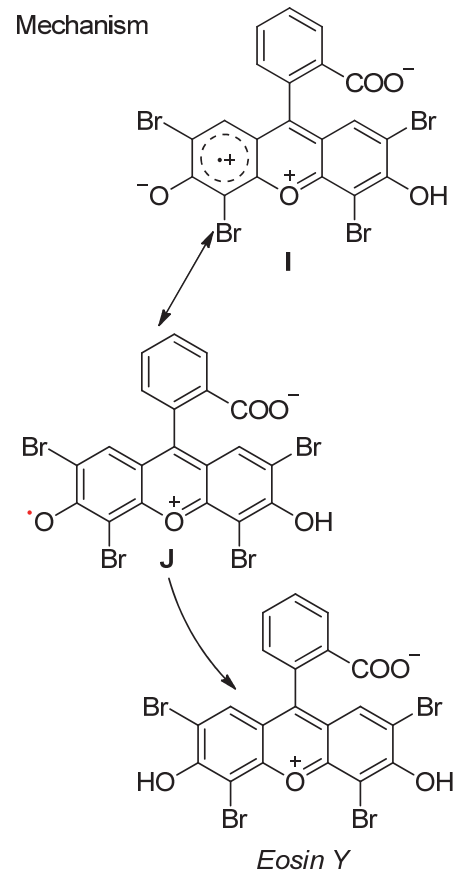

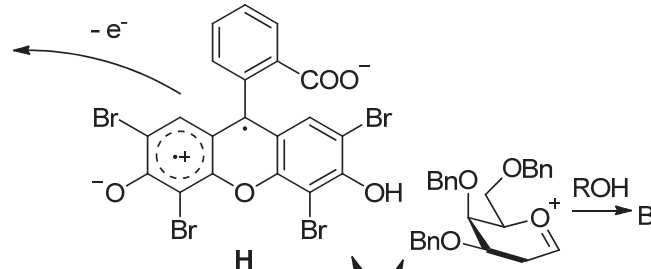

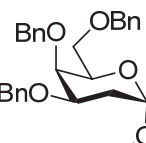

K<smiles>CCC</smiles>

L - $+{ }^{+} \cdot{ }^{-}$

.

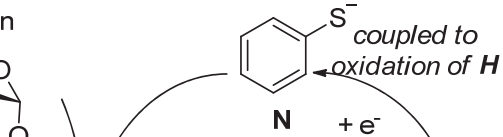

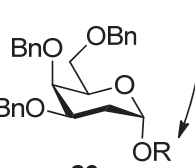
$\mathrm{H}^{+}$ $\mathrm{H}^{s_{S}}$

图式 12 EosinY 和 $\mathrm{PhSSPh}$ 介导的光促进糖基化反应

Scheme 12 EosinY and PhSSPh mediated photo-promoted glycosylation
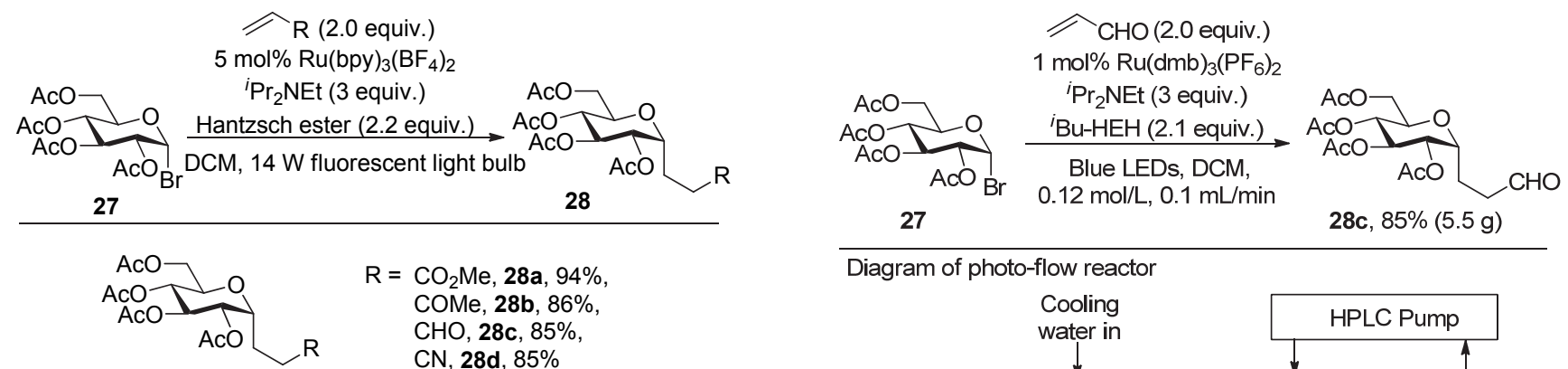

Diagram of photo-flow reactor

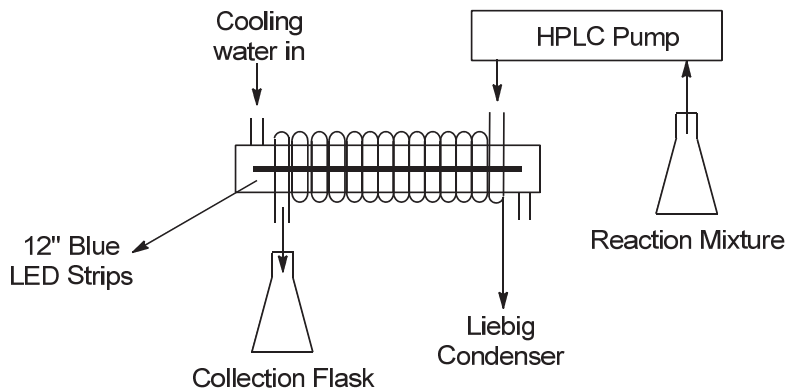

图式 $14 \mathrm{Ru}(\mathrm{dmb})_{3}\left(\mathrm{PF}_{6}\right)_{2}$ 介导的碳糖苷的形成及反应器示意图 Scheme $14 \mathrm{Ru}(\mathrm{dmb})_{3}\left(\mathrm{PF}_{6}\right)_{2}$ mediated C-glycoside formation and diagram of photo-flow reactor

图式 $13 \mathrm{Ru}(\mathrm{bpy})_{3}\left(\mathrm{BF}_{4}\right)_{2}$ 介导的碳糖苷的形成

Scheme $13 \mathrm{Ru}(\mathrm{bpy})_{3}\left(\mathrm{BF}_{4}\right)_{2}$ mediated C-glycoside formation

氧化还原过程受反应管的直径和光催化剂浓度的影响 较大，减小反应管的直径和降低催化剂的浓度均可使反 
应效率提高 ${ }^{[27]}$.

Furuta、Crich 等 ${ }^{[20,21]}$ 科研工作者使用硒糖苷供体在 紫外光促进下, 结合使用非金属催化剂合成了多种氧糖 苷化合物. 随着金属光催化剂介导的光催化反应的发 展，2013 年 Ragains 研究小组 ${ }^{[28]}$ 应用全苄基保护的硒糖 苷供体 29, 使用 $\mathrm{Ru}(\mathrm{bpy})_{3}\left(\mathrm{PF}_{6}\right)_{2}$ 或二苯基二硒醚为光催 化剂, 在蓝色 LED 灯照射下成功合成了氧糖苷类化合 物, 产物以 $\alpha$-构型为主. 相对于二苯基二硒醚, $\mathrm{Ru}(\mathrm{bpy})_{3}\left(\mathrm{PF}_{6}\right)_{2}$ 为光催化剂时反应速率更快(Scheme 15).

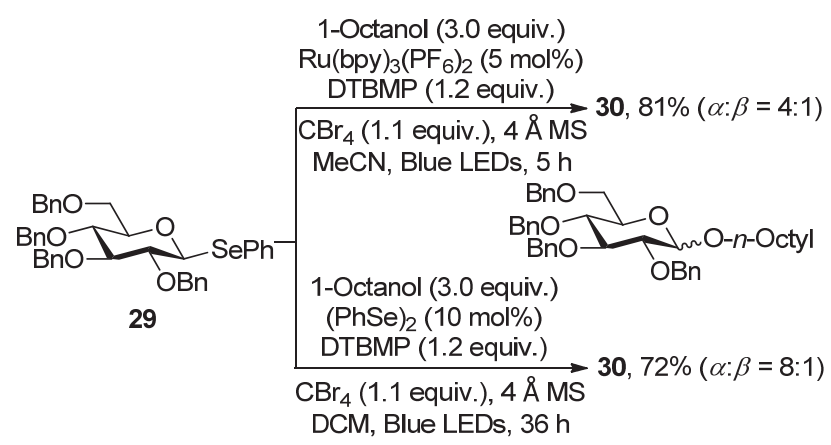

图式 $15 \mathrm{Ru}(\mathrm{bpy})_{3}\left(\mathrm{PF}_{6}\right)_{2}$ 和二苯基二硒醚介导的糖基化反应

Scheme $15 \mathrm{Ru}(\mathrm{bpy})_{3}\left(\mathrm{PF}_{6}\right)_{2}$ and $(\mathrm{PhSe})_{2}$ mediated glycosylation

硫糖苷供体具有一定还原能力, 已经被成功应用于 紫外光促进的糖基化反应中. 2013 年 Bowers 研究小 组 ${ }^{[29]}$ 成功将其应用于可见光催化糖基化反应中. 作者 以 $\operatorname{Ir}\left[\mathrm{dF}\left(\mathrm{CF}_{3}\right) \mathrm{ppy}\right]_{2}(\mathrm{dtbbpy}) \mathrm{PF}_{6}$ 为光催化剂, 催化量三氯 溴甲烷或者四溴化碳为引发剂, 六氟异丙醇(HIFP)为非 亲核质子添加剂, 在蓝色 LED 灯照射下合成了多种氧 糖苷化产物, 产物立体构型受热力学控制. 其中, 全乙 酰基保护的硫苷供体由于氧化还原电位过高不能被活 化, 而 3,4-二乙酰基-2,6-二脱氧硫苷供体由于较高的端 基电子云密度能够被顺利活化(Scheme 16).

2016 年, 叶新山课题组 ${ }^{[17]}$ 发展了一种紫外光促进 三氟甲基加成的糖苷化方法. 该课题组也进一步应用可 见光与金属光催化剂 $\mathrm{Ru}(\mathrm{bpy})_{3}\left(\mathrm{PF}_{6}\right)_{2}$ 代替紫外光, 在室 温条件下同样高效地得到糖苷化产物, 最终通过调控供 体活性，“一锅” 以 $52 \%$ 的产率得到了三糖产物 $\mathbf{1 2 b}$ (Scheme 17).

唾液酸是一类具有重要生物活性的分子，存在于多 糖、糖蛋白、糖脂等物质中, 参与多种生理和病理过程. 相较于其他类型硫苷供体，唾液酸类型的硫苷供体反应 活性差、活化难度大, 并且由于 C-3 位缺少邻基参与基 团使得糖苷化产物立体构型较难控制. 2016 年叶新山课 题组 ${ }^{[30]}$ 在前期研究的基础上发展了一种金属催化剂参 与的可见光催化法合成 $O$-唾液酸苷的方法. 作者使用 $\mathrm{Ru}(\mathrm{bpy})_{3}\left(\mathrm{PF}_{6}\right)_{2}$ 为光催化剂, Umemto's 试剂为三氟甲基 自由基前体试剂, 三氟甲磺酸铜为添加剂, 二氯甲烷和 乙腈为共溶剂, 在一 $30{ }^{\circ} \mathrm{C}$ 、蓝色 LED 灯照射下, 高产

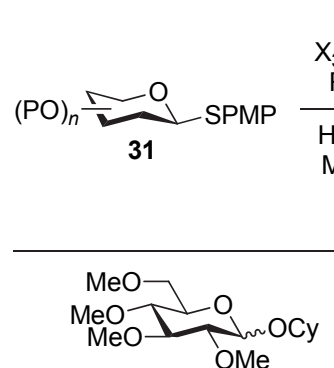

32a, $87 \%(\alpha: \beta=1.6: 1)$

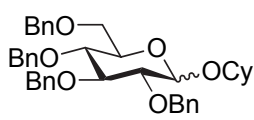

32c, $66 \%(\alpha: \beta=1: 1.5)$
Cat. $(5 \mathrm{~mol} \%)$

$\mathrm{X}_{3} \mathrm{CBr}(0.25$ equiv. $)$

$\mathrm{ROH}(2.0$ equiv.)

HIFP (10.0 equiv.)

MeCN, Blue LEDs

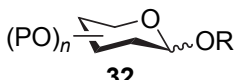

32

$\mathrm{PMP}=(p$-methoxy $)$ phenyl Cat. $=\operatorname{Ir}\left[\mathrm{dF}\left(\mathrm{CF}_{3}\right) \mathrm{ppy}\right]_{2}(\mathrm{dtbbpy}) \mathrm{PF}_{6}$

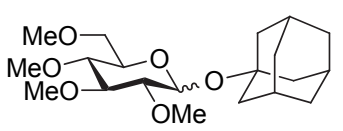

32b, $71 \%(\alpha: \beta=1.6: 1)$

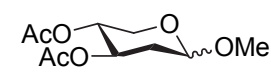

32d, $82 \%(\alpha: \beta=1: 4.1)$

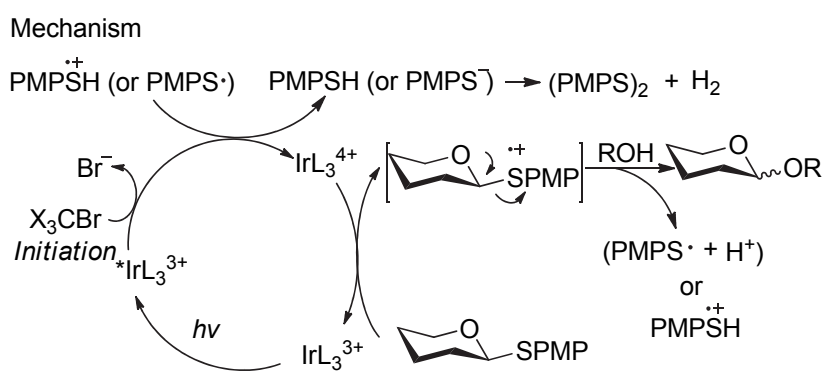

图式 $16 \operatorname{Ir}\left[\mathrm{dF}\left(\mathrm{CF}_{3}\right) \mathrm{ppy}\right]_{2}(\mathrm{dtbbpy}) \mathrm{PF}_{6}$ 介导的光促进糖基化反应 Scheme $16 \operatorname{Ir}\left[\mathrm{dF}\left(\mathrm{CF}_{3}\right) \text { ppy }\right]_{2}(\mathrm{dtbbpy}) \mathrm{PF}_{6}$ mediated glycosylation

$\mathrm{R}^{1} \mathrm{OH}$ (1.0 equiv.) $\mathrm{Ru}(\mathrm{bpy})_{3}\left(\mathrm{PF}_{6}\right)_{2}(0.05$ equiv. $)$ $\mathrm{Cu}(\mathrm{OTf})_{2}(1.5$ equiv.)

Umemoto's reagent ( 2.6 equiv.)
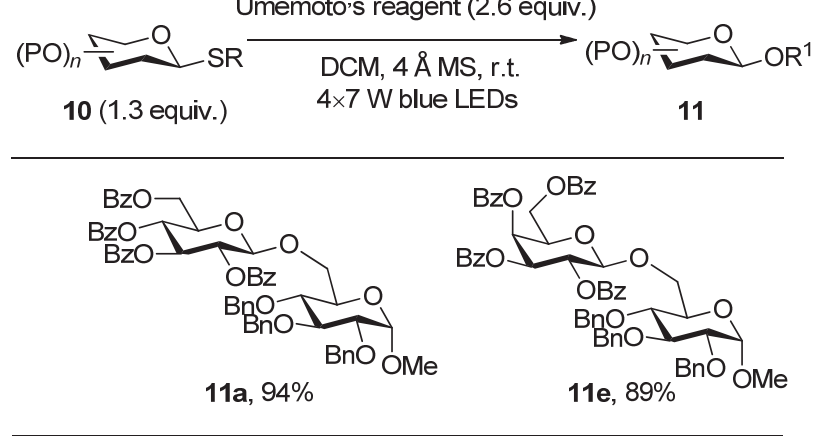

Trisaccharide $12 b$

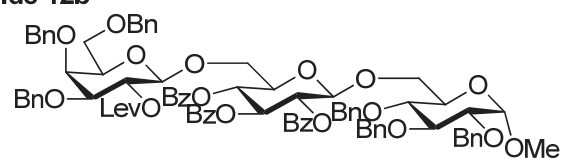

图式 17 可见光促进的自由基加成糖基化反应

Scheme 17 Visible light-mediated glycosylation through radical addition pathway

率、高 $\alpha$-选择性地合成多种氧唾液酸苷化产物. 其中乙 腈对稳定糖基碳正离子有重要作用，反应温度对反应产 率有较大影响, 温度高于或者低于 $-30{ }^{\circ} \mathrm{C}$ 都会使得产 率明显下降(Scheme 18). 

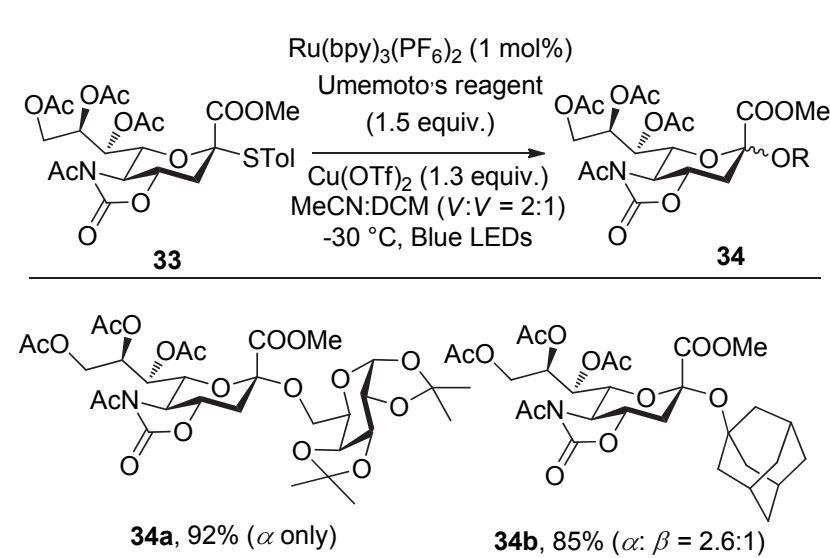

Mechanism

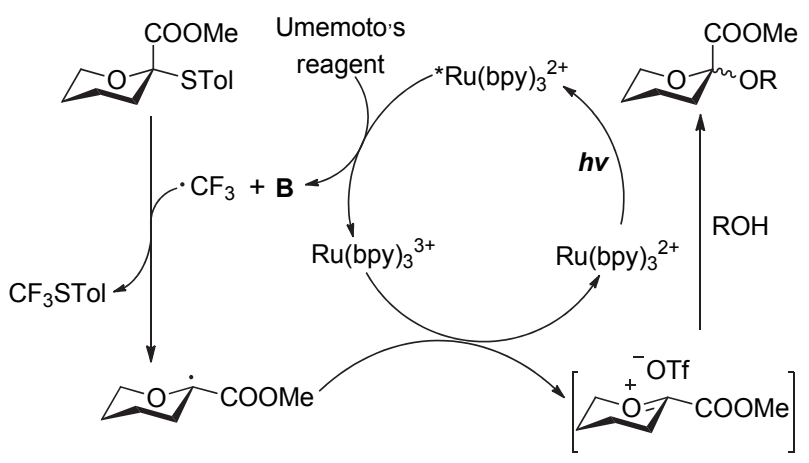

图式 $18 \mathrm{Ru}(\mathrm{bpy})_{3}\left(\mathrm{PF}_{6}\right)_{2}$ 介导的唾液酸苷合成反应

Scheme $18 \mathrm{Ru}(\mathrm{bpy})_{3}\left(\mathrm{PF}_{6}\right)_{2}$ mediated sialylation reaction

早在 1985 年, Noyori 等 ${ }^{[18]}$ 就已提出了只需光催化剂 作用即可完成光催化糖基化的策略, 但此后的光促进糖 基化方法为了保证合成效率, 大都需要添加额外的氧化 剂或者还原剂, 直到 2017 年 Crich 课题组才有所突破. Knowles 等 ${ }^{[31]}$ 研究发现, 自由基捕获剂 TEMPO 衍生的 烷氧基氨类化合物的 $\mathrm{C}-\mathrm{O}$ 键较容易断裂, 并且该类化 合物可以在可见光和 $\left[\operatorname{Ir}\left(\mathrm{dF}\left(\mathrm{CF}_{3}\right) \mathrm{ppy}\right)_{2}\left(\mathrm{~d}\left(\mathrm{CF}_{3}\right) \mathrm{bpy}\right)\right] \mathrm{PF}_{6}$ 的 催化下生成碳正离子中间体和稳定的 TEMPO 自由基. 基于此, Crich 课题组 ${ }^{[32]}$ 通过构建糖基供体 35, 在仅使用 金属光催化剂 $\operatorname{Ir}\left[\mathrm{dF}\left(\mathrm{CF}_{3}\right) \mathrm{ppy}\right]_{2}(\mathrm{dtbbpy}) \mathrm{PF}_{6}$ 和可见光照射 下，实现了各类氧糖苷化合物的高效合成. 在该反应中, 糖基供体 35 被激发态的光催化剂* ${ }^{3}{ }^{3+}$ 氧化成自由基阳 离子中间体 $\mathbf{O}, \mathbf{O}$ 进一步裂解成氧鎓离子和氧自由基 $\mathbf{P}$, 随后 $\mathbf{P}$ 被还原态光催化剂 $\mathrm{Ir}^{2+}$ 还原成氧负离子中间体 $\mathbf{Q}$, 而催化剂则完成一次催化循环; 与此同时, 氧鎓离 子则会与受体反应生成糖苷化产物 36 (Scheme 19). 其 中, 反应溶剂硝基甲烷的使用是高糖基化效率的保证; 分子篮的使用不仅可以有效减少水解产物的生成, 而且 可以加快反应速率.

上述光促进的糖基化方法大多需要构建带有特定 离去基的糖基供体, 如卤代糖、硫苷、三氯乙酰亚胺酯 供体等. 2018 年, 肖文精课题组 ${ }^{[33]}$ 报道了以端基未保护 的糖基半缩醛为供体的酚苷的合成方法. 该方法以 $\operatorname{Ir}\left[\mathrm{dF}\left(\mathrm{CF}_{3}\right) \text { ppy }\right]_{2}(\mathrm{dtbbpy}) \mathrm{PF}_{6}$ 为氧化还原催化剂、 $\mathrm{NiCl}_{2}$ •

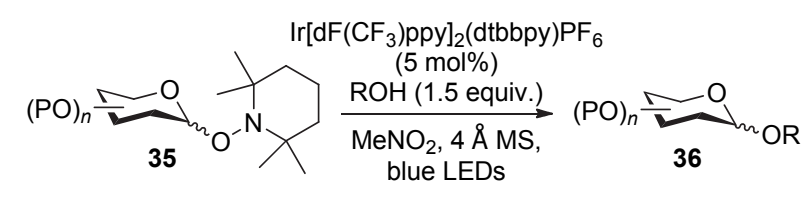

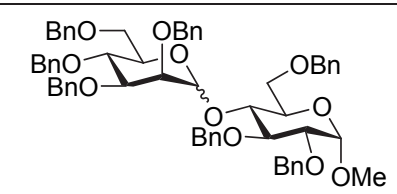

36a, $64 \%(\alpha: \beta=1: 1)$

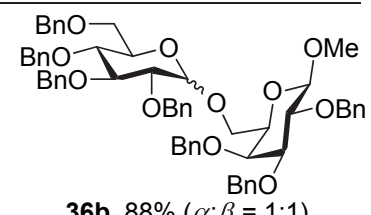

36b, $88 \%(\alpha: \beta=1: 1)$

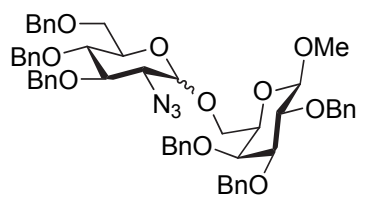

36d, $61 \%(\alpha: \beta=1.4: 1)$

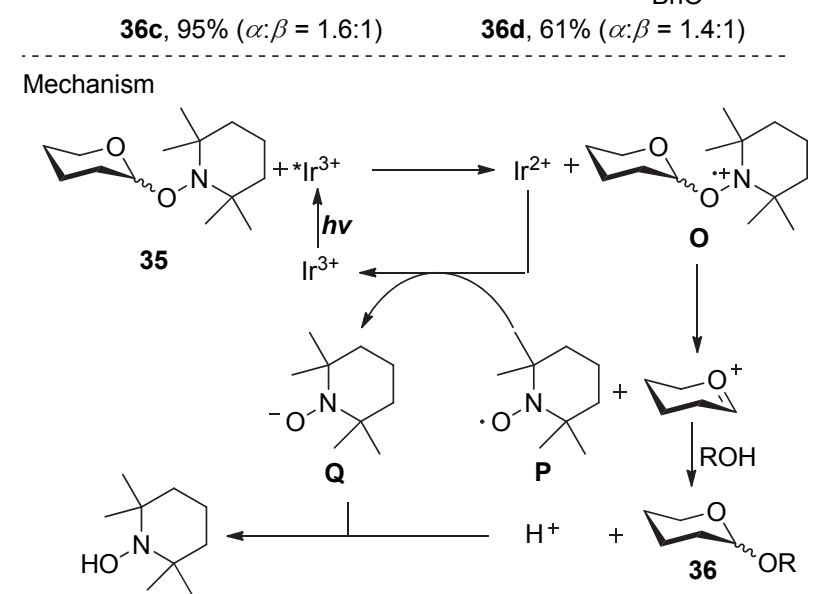

图式 19 无添加剂的可见光催化糖基化反应

Scheme 19 Visible-light promoted photocatalytic glycosylation without additives

glyme 为过渡金属催化剂、DABCO 为胺类还原剂, 通过 基于单电子转移的可见光氧化还原/过渡金属 $\mathrm{Ni}$ 双催化 体系, 成功实现了糖基半缩醛与芳基溴化物的偶联 (Scheme 20). 该方法适用于醚键保护的各式糖基供体 和连有吸电子基团的芳基(苯基、吡啶基)溴代物的偶联. 受异头碳效应的影响, 产物以热力学稳定的 $\alpha$ 构型为主.

\section{3 “电子供体-受体复合物” 促进的糖基化反应}

一般可见光促进的糖基化反应离不开光催化剂的 参与, 但由于金属光催化剂价格较为昂贵, 这在一定程 度上限制了此类反应的应用. 近年来，一种新型的 “电 子供体-受体复合物” 理论被广泛应用到了有机合成反

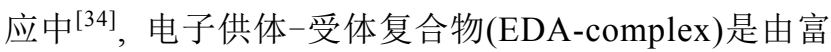
电子分子(电子供体)和缺电子分子(电子受体)之间通过 离散控制、基态结合而产生的. EDA 复合物有时具有可 见光响应能力, 在这种情况下, 电子传递无需光催化剂 的参与就能实现. 2016 年 Ragains 课题组 ${ }^{[35]}$ 发展了一种 基于 EDA 复合物理论的可见光促进的糖基化反应. 作 者通过实验和理论计算(DFT)证明供体 39 与 Umemoto's 试剂之间形成了 EDA 复合物，该复合物可以在可见光 

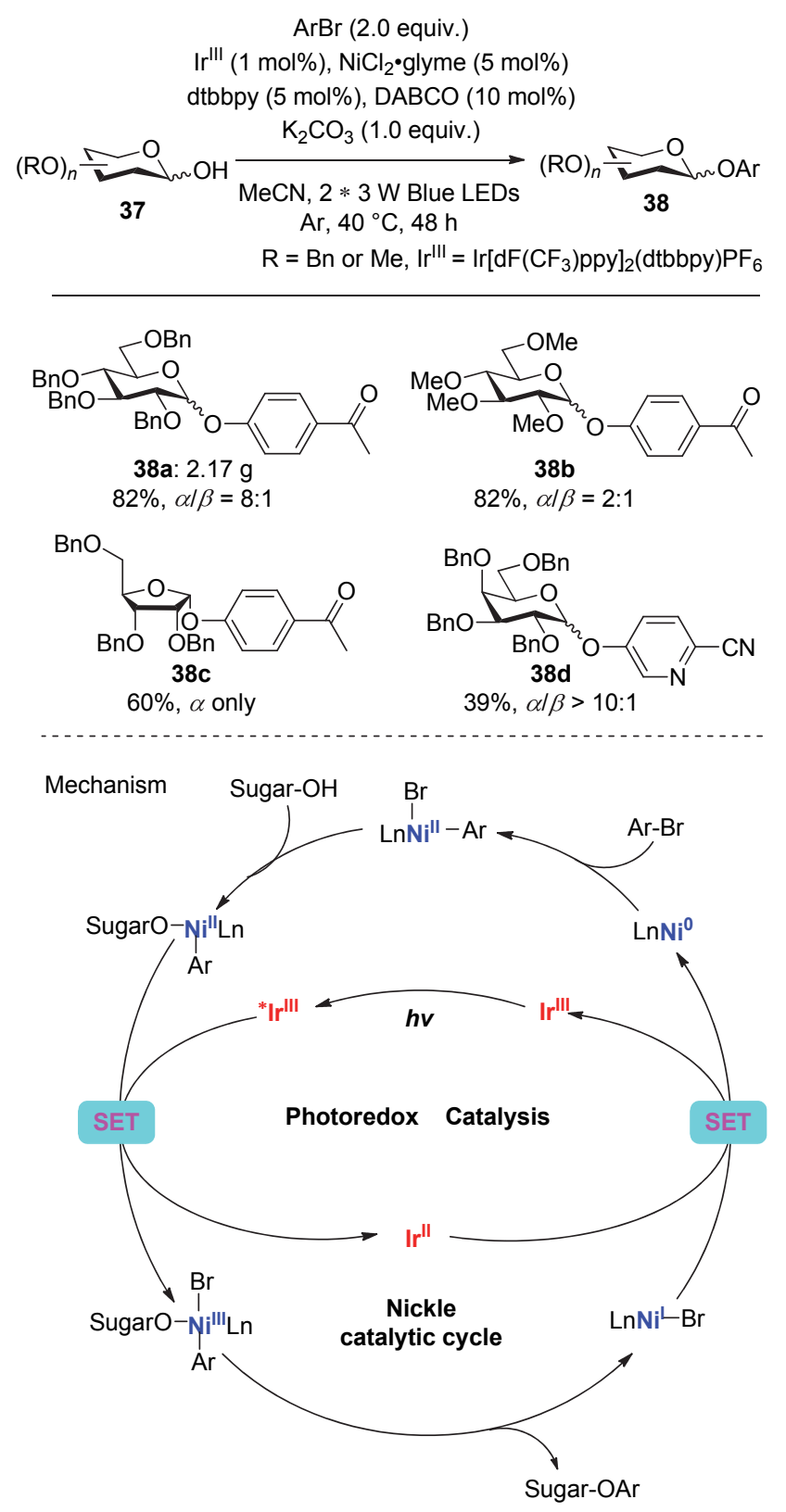

图式 20 双催化体系下糖基半缩醛与芳基溴代物的糖基化反应

Scheme 20 Glycosylation of sugar lactols with aryl bromides via dual catalysis

作用下发生单电子转移, 产生化合物 $\mathbf{B}$ 和硫正离子中间 体 $\mathbf{R}$, 随后后者离去四氢噻吩生成氧鎓离子 $\mathbf{E}$, 而氧鎓 离子 $\mathbf{E}$ 可与受体作用生成目标糖苷 40. 另外, 增加糖基 供体用量和提高反应浓度均可以提高反应产率; 使用具 有邻基参与基团的糖基供体可以高 $\beta$-选择性的得到糖 苷化产物. 此外, 1-辛基硫苷、茮基硫苷等供体对反应条 件具有耐受性(Scheme 21).

\section{4 总结与展望}

糖类化合物是生物体赖以生存的能量来源和结构 物质. 伴随光催化反应在有机合成中的发展, 光促进的

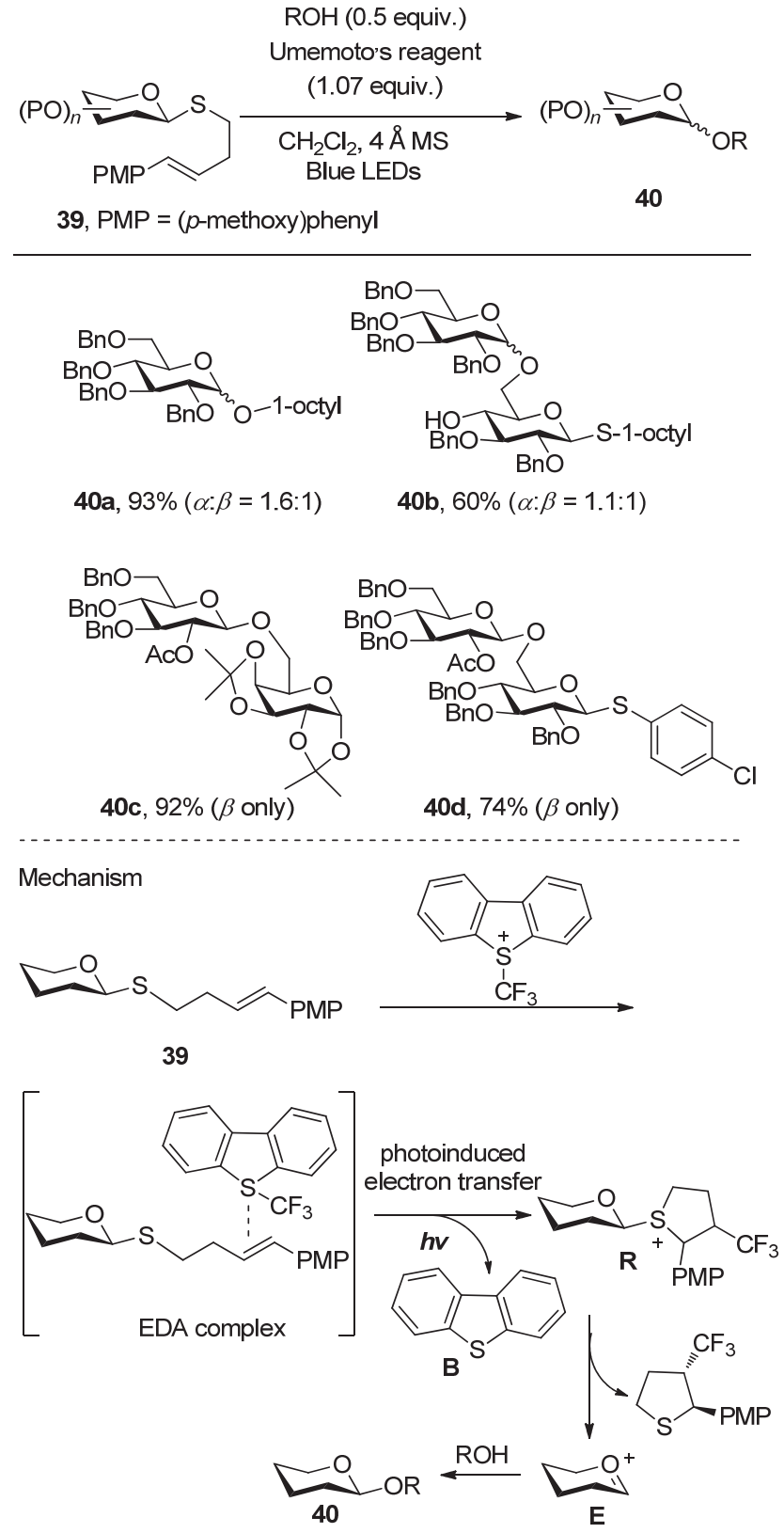

图式 21 可见光促进的 “电子供体-受体复合物” 历程的氧糖苷化反 应

Scheme 21 Visible-light-promoted $O$-glycosylation via EDA complex

糖基化反应也引起了化学工作者的极大兴趣. 近年来, 在 “绿色化学” 理念的催使下, 紫外光和可见光促进的 糖基化合成反应取得了长足的发展. 光促进的糖基化反 应为糖类化合物的合成提供了一种新的可能，但是仍然 面临着巨大挑战: (1)如何使得反应条件更加温和; (2)如 何在高效构建复杂糖苷键的同时规模化合成相应的糖 苷化产物; (3)能否在无外加氧化剂或还原剂的情况下实 现糖苷键的构建等. 相信在不久的将来, 在科研工作者 们的努力下，随着新型光敏剂的发现、光催化、糖苷化 理论研究的深入及方法的多样化, 光促进的糖基化反应 会有更长远的发展与应用. 


\section{作者简介}

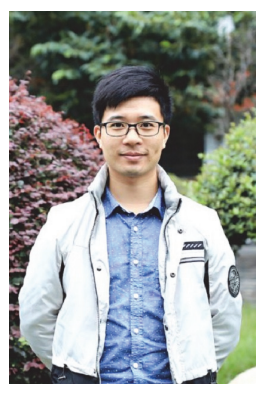

王浩, 山东临沂人, 2012 年于烟台大学获学士学位, 2018 年于华中科技大学获博士学位, 师从万谦教授, 主要从事可 见光介导的自由基还原反应及其在脱氧糖合成中的应用研究.

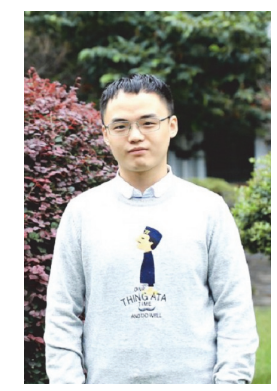

吴品儒, 浙江温州人, 2017 年于华中科技大学获学士学位, 同年于华中科技大学继续攻读硕士学位, 师从万谦教授, 主 要从事糖合成方法学及室糖合成研究.

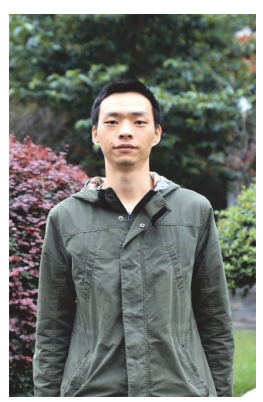

赵祥, 安徽阜阳人, 2015 年于华中科技大学获学士学位, 同年于华中科技大学继续攻读博士学位, 师从万谦教授, 主 要从事可见光介导的自由基还原反应机理及应用研究.

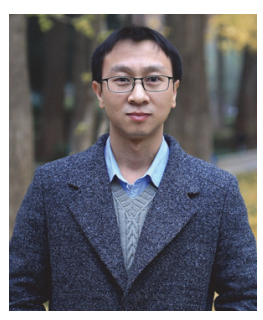

曾静, 湖北利川人; 2004 年于东南大学获学士学位; 2007 年于厦门大学获硕士学位, 2013 年于南洋理工大学获博士学 位, 师从 Liu Xue-wei 教授; 同年加入华中科技大学药学院, 主要从事糖化学及糖类药物的研究.

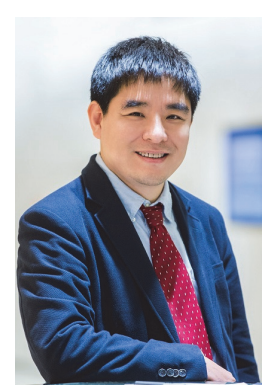

万谦, 湖北武汉人; 1997 年于华中师范大学获学士学位; 2004 年于巴黎第十一大学获博士学位, 师从 André Lubineau 教授; 同年加入美国斯隆一凯特林癌症研究中心 Samuel J. Danishefsky 课题组从事博士后研究; 2012 年至今于华中科技 大学药学院开展独立研究工作. 主要从事糖化学、自由基化学 及药物化学等研究.

\section{References}

[1] (a) Cai, M.-S.; Li, Z.-J. Carbohydrate Chemistry, Chemical Industry Press, Beijing, 2007, pp. 1 33. (蔡孟深, 李中军, 糖化学, 化学 工业出版社, 北京, 2007, pp. 1 33.) (b). Kong, F.-Z. Carbohydrate Chemistry, Science Press, Beijing, 2005, pp. 1 41. (孔繁祚, 糖化学, 科学出版社, 北京, 2005, pp. 1 41.)

[2] Guo, Z.; Wang, L. Prog. Chem. 1995, 7, 10. (郭忠武, 王来䂀, 化 学进展, 1995, 7, 10.)

[3] Varki, A.; Cummings, R.-D.; Esko, J.-D.; Freeze, H.-H.; Stanley, P.; Bertozzi, C.-R.; Hart, G.-W.; Etzler, M.-E. Essential of Glycobiology, Cold Spring Harbor Laboratory Press, 2008, pp. $1 \sim 21$.

[4] Chen, L.-Q.; Lai, D.; Song, Z.-W.; Zhao, X.-E.; Kong, F.-Z. Chin. J. Org. Chem. 2006, 26, 627. (陈朗秋, 赖端, 宋志伟, 赵兴俄, 孔繁 祚, 有机化学, 2006, 26, 627.)

[5] Fischer, E. Chem. Ber. 1893, 26, 2400.

[6] (a) Koenigs, W.; Knorr, E. Chem. Ber. 1901, 34, 957. (b) Schmidt, R. R.; Michel, J. Angew. Chem. 1980, 92, 763. (c) Geng, Y.; Zhang, L.-H.; Ye, X.-S. Chem. Commun. 2008, 5, 597. (d) Raghavan, S.; Kahne, D. J. Am. Chem. Soc. 1993, 115, 1580. (e) Tang, Y.; Li, J.; Zhu, Y.; Li, Y.; Yu, B. J. Am. Chem. Soc. 2013, 135, 18396.

[7] (a) Shu, P.; Xiao, X.; Zhao, Y.; Xu, Y.; Yao, W.; Tao, J.; Wang, H.; Yao, G.; Lu, Z.; Zeng, J.; Wan, Q. Angew. Chem., Int. Ed. 2015, 54, 14432. (b) Xiao, X.; Zhao, Y.; Shu, P.; Zhao, X.; Liu, Y.; Sun, J.; Zhang, Q.; Zeng, J.; Wan, Q. J. Am. Chem. Soc. 2016, 138, 13402. (c) Hu, Y.; Yu, K.; Shi, L.-L.; Liu, L.; Sui, J.-J.; Liu, D.-Y.; Xiong, B.; Sun, J.-S. J. Am. Chem. Soc. 2017, 139, 12736. (d) Wang, H.-Y.; Simmons, C. J.; Blaszczyk, S. A.; Balzer, P. G.; Luo, R.; Duan, X.; Tang, W. Angew. Chem., Int. Ed. 2017, 56, 15698. (e) Wadzinski, T. J.; Steinauer, A.; Hie, L.; Pelletier, G.; Schepartz, A.; Miller, S. J. Nature Chem. 2018, 10, 644.

[8] (a) Xu, Y.; Zhang, J.; Dong, Y.; Tan, W. Chin. J. Org. Chem. 2017, 37, 2929. (许一仁, 张建军, 董燕红, 谭伟明, 有机化学, 2017, 37, 2929.) (b) Ren, H.; Tao, J.; An, H. Chin. J. Org. Chem. 2018, 38, 138. (任行, 陶京朝, 安浩云, 有机化学, 2018, 38, 138.) (c) Shen, R.; Cao, X.; Yu, B. Acta Chim. Sinica 2018, 76, 278. (沈仁增，曹金铨, 俞谜, 化学学报, 2018, 76, 278.) (d) Zhua, D.; Yu, B. Chin. J. Chem. 2018, 36, 681 .

[9] Nicewicz, D. A.; MacMillan, D. W. C. Science 2008, 322, 77.

[10] Ischay, M. A.; Anzovino, M. E.; Du, J.; Yoon, T. P. J. Am. Chem. Soc. 2008, 130, 12886 .

[11] Nguyen, J. D.; D'Amato, E. M.; Narayanam, J. M. R.; Stephenson, C. R. J. Nat. Chem. 2012, 4, 854.

[12] Xuan, J.; Xiao, W.-J. Angew. Chem., Int. Ed. 2012, 51, 6828.

[13] (a) Sangwan, R.; Mandal, P. K. RSC Adv. 2017, 7, 26256. (b) Ye, H.; Xiao, C.; Lu, L. Chin. J. Org. Chem. 2018, 38, 1897. (叶辉, 肖聪, 陆良秋, 有机化学, 2018, 38, 1897.)

[14] Yamago, S.; Miyazoe, H.; Yoshida, J.-i. Tetrahedron Lett. 1999, 40, 2339.

[15] Nakanishi, M.; Takahashi, D.; Toshima, K. Org. Biomol. Chem. 2013, $11,5079$.

[16] Mao, R.-Z.; Guo, F.; Xiong, D.-C.; Li, Q.; Duan, J.; Ye, X.-S. Org. Lett. 2015, 17, 5606. 
[17] Mao, R.-Z.; Xiong, D.-C.; Guo, F.; Li, Q.; Duan, J.; Ye, X.-S. Org. Chem. Front. 2016, 3, 737.

[18] Hashimoto, S.; Kurimoto, I.; Fujii, Y.; Noyori, R. J. Am. Chem. Soc. $1985,107,1427$

[19] Griffin, G. W.; Bandara, N. C.; Clarke, M. A.; Tsang, W.-S.; Garegg, P. J.; Oscarson, S.; Silwanis, B. A. Heterocycles 1990, 30, 939.

[20] Furuta, T.; Takeuchi, K.; Iwamura, M. Chem. Commun. 1996, 147, 157.

[21] Cumpstey, I.; Crich, D. J. Carbohydr. Chem. 2011, 30, 469.

[22] Iwata, R.; Uda, K.; Takahashi, D.; Toshima, K. Chem. Commun. 2014, 50, 10695 .

[23] Kimura, T.; Eto, T.; Takahashi, D.; Toshima, K. Org. Lett. 2016, 18 , 3190.

[24] (a) Balmond, E. I.; Coe, D. M.; Galan, M. C.; McGarrigle, E. M. Angew. Chem., Int. Ed. 2012, 51, 9152. (b) Balmond, E. I.; Benito-Alifonso, D.; Coe, D. M.; Alder, R. W.; McGarrigle, E. M.; Galan, M. C. Angew. Chem., Int. Ed. 2014, 53, 8190. (c) Sau, A.; Williams, R.; Palo-Nieto, C.; Franconetti, A.; Medina, S.; Galan, M. C. Angew. Chem., Int. Ed. 2017, 56, 3640. (d) Palo-Nieto, C.; Sau, A.; Galan, M. C. J. Am. Chem. Soc. 2017, 139, 14041.

[25] Zhao, G.; Wang, T. Angew. Chem., Int. Ed. 2018, 57, 6120.
[26] Andrews, R. S.; Becker, J. J.; Gagné, M. R. Angew. Chem., Int. Ed. 2010, 49, 7274.

[27] Andrews, R. S.; Becker, J. J.; Gagné, M. R. Angew. Chem., Int. Ed. 2012, 51,4140 .

[28] Spell, M.; Wang, X.; Wahba, A. E.; Conner, E.; Ragains, J. Carbohydr. Res. 2013, 369, 42.

[29] Wever, W. J.; Cinelli, M. A.; Bowers, A. A. Org. Lett. 2013, 15, 30.

[30] Yu, Y.; Xiong, D.-C.; Mao, R.-Z.; Ye, X.-S. J. Org. Chem. 2016, 8, 7134.

[31] Zhu, Q.; Gentry, E. C.; Knowles, R. R. Angew. Chem., Int. Ed. 2016, $55,9969$.

[32] Wen, P.; Crich, D. Org. Lett. 2017, 19, 2402.

[33] Ye, H.; Xiao, C.; Zhou, Q.-Q.; Wang, P. G.; Xiao, W.-J. J. Org. Chem. 2018, 83, 13325.

[34] (a) Arceo, E.; Jurberg, I. D.; Álvarez-Fernández, A.; Melchiorre, P. Nat. Chem. 2013, 5, 750. (b) Lima, C. G. S.; Lima, T. de M.; Duarte, M.; Jurberg, I. D.; Paixão, M. W. ACS Catal. 2016, 6, 1389.

[35] Spell, M. L.; Deveaux, K.; Bresnahan, C. G.; Bernard, B. L.; Sheffield, W.; Kumar, R.; Ragains, J. R. Angew. Chem., Int. Ed. 2016, 55,6515 . 